Article

\title{
Aqueous Fe(II)-Induced Phase Transformation of Ferrihydrite Coupled Adsorption/Immobilization of Rare Earth Elements
}

\author{
Yingheng Fei ${ }^{1,2}$, Jian Hua ${ }^{1}$, Chengshuai Liu ${ }^{3, *}$, Fangbai Li ${ }^{1}$, Zhenke Zhu ${ }^{4}$, Tangfu Xiao ${ }^{2}$, \\ Manjia Chen ${ }^{1}$, Ting Gao ${ }^{1,3}$, Zhiqi Wei ${ }^{1}$ and Likai Hao ${ }^{3}$ \\ 1 Guangdong Key Laboratory of Integrated Agro-environmental Pollution Control and Management, \\ Guangdong Institute of Eco-Environmental Sciences \& Technology, Guangzhou 510650, China; \\ yhfei@gzhu.edu.cn (Y.F.); huajianyh1211@163.com (J.H.); cefbli@soil.gd.cn (F.L.); mjchen@soil.gd.cn (M.C.); \\ gaoting_gt0@163.com (T.G.); weizhiq123@126.com (Z.W.) \\ 2 Key Laboratory for Water Quality and Conservation of the Pearl River Delta, Ministry of Education, \\ School of Environmental Science and Engineering, Guangzhou University, Guangzhou 510006, China; \\ xiaotangfu@vip.gyig.ac.cn \\ 3 State Key Laboratory of Environmental Geochemistry, Institute of Geochemistry, Chinese Academy of \\ Sciences, Guiyang 550081, China; haolikai@mail.gyig.ac.cn \\ 4 Key Laboratory of Agro-Ecological Processes in Subtropical Region, Institute of Subtropical Agriculture, \\ Chinese Academy of Sciences, Changsha 410125, China; zhuzhenke@isa.ac.cn \\ * Correspondence: liuchengshuai@vip.gyig.ac.cn; Tel.: +86-851-8589-1334
}

Received: 30 June 2018; Accepted: 15 August 2018; Published: 18 August 2018;

\begin{abstract}
The phase transformation of iron minerals induced by aqueous $\mathrm{Fe}(\mathrm{II})\left(\mathrm{Fe}(\mathrm{II})_{a q}\right)$ is a critical geochemical reaction which greatly affects the geochemical behavior of soil elements. How the geochemical behavior of rare earth elements (REEs) is affected by the $\mathrm{Fe}(\mathrm{II})_{a q}$-induced phase transformation of iron minerals, however, is still unknown. The present study investigated the adsorption and immobilization of REEs during the $\mathrm{Fe}(\mathrm{II})_{a q}$-induced phase transformation of ferrihydrite. The results show that the heavy REEs of Ho(III) were more efficiently adsorbed and stabilized compared with the light REEs of $\mathrm{La}$ (III) by ferrihydrite and its transformation products, which was due to the higher adsorptive affinity and smaller atomic radius of $\mathrm{Ho}(\mathrm{III})$. Both $\mathrm{La}(\mathrm{III})$ and $\mathrm{Ho}(\mathrm{III})$ inhibited the Fe atom exchange between $\mathrm{Fe}(\mathrm{II})_{a q}$ and ferrihydrite, and sequentially, the $\mathrm{Fe}(\mathrm{II})_{a q}$-induced phase transformation rates of ferrihydrite, because of the competitive adsorption with $\mathrm{Fe}(\mathrm{II})_{a q}$ on the surface of iron (hydr)oxides. Owing to the larger amounts of adsorbed and stabilized $\mathrm{Ho}(\mathrm{III})$, the inhibition of the $\mathrm{Fe}(\mathrm{II})_{a q}$-induced phase transformation of ferrihydrite affected by $\mathrm{Ho}$ (III) was higher than that by $\mathrm{La}(\mathrm{III})$. Our findings suggest an important role for the $\mathrm{Fe}(\mathrm{II})_{a q}$-induced phase transformation of iron (hydr)oxides in assessing the mobility and transfer behavior of REEs, as well as for their occurrence in earth surface environments.
\end{abstract}

Keywords: ferrihydrite; recrystallization; REEs; stabilization; Fe atom exchange

\section{Introduction}

The aqueous $\mathrm{Fe}(\mathrm{II})\left(\mathrm{Fe}(\mathrm{II})_{a q}\right)$-induced phase transformation of iron (hydr)oxides is one of the most important reactions in the soil iron cycle and imposes great effects on the environmental behaviors of metals [1]. It was proposed in the 1980s that Fe(II) $)_{a q}$ could catalyze the phase transformation of iron (hydr)oxides through electron transfer and atom exchange with structural $\mathrm{Fe}(\mathrm{III})$ ( $\mathrm{Fe}(\mathrm{III})_{\text {oxide }}$ ) [2]. However, only in the last two decades has this process been confirmed by ${ }^{57} \mathrm{Fe}$ isotopic tracer and 
spectroscopic investigations [3,4]. In the presence of Fe(II) $)_{a q}$, atom exchange occurs between Fe(II) $)_{a q}$ and $\mathrm{Fe}(\mathrm{III})_{\text {oxide, }}$, when Fe(II) $)_{a q}$ was sorbed on or into the oxide crystal and then oxidized and became a secondary Fe(III) $)_{\text {oxide }}$, while a portion of primary Fe(III) $)_{\text {oxide }}$ would be reduced and released as Fe(II) $)_{a q}$. Such reactions would accelerate the phase transformation of iron (hydr)oxides to more stable phases, e.g., goethite, magnetite and hematite [4,5]. Coexisting metallic ions in the system might also be involved via adsorption, enwrapping and substitution, and hence influence the phase transformation process; once the metallic ions were fixed in the iron (hydr)oxides, their environmental mobility and bioavailability were eventually altered $[5,6]$.

Ferrihydrite is a form of iron (hydr)oxide which is usually first formed in the course of iron mineralization and with relatively poor crystallinity [7]. Featuring a small particle size, large specific surface area, as well as high surface activity, ferrihydrite is often favored for metal adsorption and plays critical roles in soil element cycling [8,9]. Compared with other crystalline iron (hydr)oxides, ferrihydrite is thermodynamically unstable and can be readily recrystallized to lepidocrocite, goethite and magnetite [7]. Under anaerobic conditions in sub soils, Fe(II) $a q$ generated by dissimilatory iron reduction is an important driving force for ferrihydrite transformation. Rather than the simple redox cycling of iron, the $\mathrm{Fe}(\mathrm{II})_{a q}$-induced phase transformation of ferrihydrite plays an important role in controlling the co-existing metal ions' mobilization/immobilization in the environment, since its adsorption, immobilization, transport and transformation are heavily interfered with by the interplay between $\mathrm{Fe}(\mathrm{II})_{a q}$ and $\mathrm{Fe}(\mathrm{III})_{\text {oxide }}$.

Rare earth elements (REEs) include the lanthanide family, with atomic numbers from 57 to 71 , as well as scandium and yttrium. They are predominantly trivalent (i.e., $\mathrm{Ln}^{3+}, \mathrm{Eu}^{3+}$ ), except for some which have other oxidation states which are less stable, such as cerium $\left(\mathrm{Ce}^{4+}\right)$ and europium $\left(\mathrm{Eu}^{2+}\right)$ [10]. As a result of their similar atomic radii and oxidation state, REEs can substitute each other in various mineral forms, such as in halides, carbonates, oxides, phosphates, and silicates, which results in their wide distribution within the Earth's crust [11]. Usually, REEs are also utilized as tracers of geochemical processes [12]. China, as the biggest supplier in the world, features high contents of REEs in soils, as well as using them long-term as fertilizer additives, and with uncontrolled and unplanned release by mining activities [11,13]. Iron (hydr)oxide is a promising potential carrier for REEs in the environment [14]. During the iron oxide formation and transformation, the uptake, release, and oxidation states of REEs also change accordingly [15]. Colloidal and sedimentary iron (hydr)oxides were reported to be a major factor influencing the fractionation, transport, and mobilization/immobilization of REEs in the aquatic environment [12,16]. Coexisted or structurally incorporated metal ions are universal within iron (hydr)oxides in soils. The affinity of REEs ions to iron (hydr)oxides might cause interference with the phase transformation of iron (hydr)oxides. However, related work has rarely been reported previously. Both the effects caused by REEs on Fe(II) $a q$ and $\mathrm{Fe}(\mathrm{III})_{\text {oxide }}$ interplay and the effect of iron (hydr)oxides' transformation on the environmental behavior of REEs are still unknown.

In a previous study, we found that divalent metal ions, e.g., $\mathrm{Ba}(\mathrm{II}), \mathrm{Ca}(\mathrm{II}), \mathrm{Mg}(\mathrm{II}), \mathrm{Mn}(\mathrm{II}), \mathrm{Co}(\mathrm{II})$, $\mathrm{Ni}(\mathrm{II})$ and $\mathrm{Zn}(\mathrm{II})$, inhibited the $\mathrm{Fe}(\mathrm{II})_{a q}$-induced phase transformation of ferrihydrite, while the metal ions were immobilized during this process [5]. The binding affinity of metal ions to ferrihydrite was the main factor that controlled the inhibition effects and immobilization efficiency. Besides the difference in valence, REEs are lithophile elements that are more readily combined with oxygen, while the most previously studied heavy metals are often chalcophile elements or siderophile elements, which are usually combined with sulfur or iron in the earth crust [17]. The unique characteristics of REEs imply that the interaction between REEs and iron (hydr)oxide transformation might be different, which requires specific investigation.

Therefore, in the present study, we focused on the cation effects of two typical REE ions, lanthanum (La) and holmium (Ho), as representatives of light REEs (LREEs) and heavy REEs (HREEs), respectively, on the phase transformation of ferrihydrite, as well as the stabilization of these two REEs metals during the formation of secondary iron (hydr)oxides. The mechanisms 
of the interaction between REE cations and the ferrihydrite phase transformation were explored under fixed initial Fe(II) and ion concentrations at buffered constant $\mathrm{pH}$ conditions. The fate of REE cations and the transformation rates and products of ferrihydrite were the main concerns of the study. This investigation is novel in finding out the coupling mechanisms of the phase transformation of ferrihydrite with REE immobilization.

\section{Materials and Methods}

\subsection{Ferrihydrite Preparation}

Ferrihydrite was prepared in the laboratory according to previous studies [18,19]. Firstly, $20 \mathrm{~g}$ of $\mathrm{Fe}\left(\mathrm{NO}_{3}\right)_{3} \bullet 9 \mathrm{H}_{2} \mathrm{O}$ was dissolved in $250 \mathrm{~mL}$ of double distilled de-ionized (DDI) water. Afterwards, the solution was titrated by $1 \mathrm{M} \mathrm{KOH}$ to $\mathrm{pH} 7-8$. The resulting suspension was then centrifuged. After decanting the supernatant, the remained solids were washed with DDI water. This process was repeated until the $\mathrm{pH}$ of the slurry reached the $\mathrm{pH}_{\mathrm{pzc}}(\sim \mathrm{pH} 7.5)$ of ferrihydrite. The stock suspension of ferrihydrite was stored at $4{ }^{\circ} \mathrm{C}$ and used for the $\mathrm{Fe}(\mathrm{II})$-induced phase transformation experiments within three days. A portion of the synthesized ferrihydrite was freeze-dried for the X-ray diffraction (XRD) analysis.

\subsection{Experiments of $\mathrm{Fe}(\mathrm{II})_{a q}$-Induced Transformation of Ferrihydrite}

To maintain anaerobic conditions, all transformation experiments were carried out inside an anoxic chamber (Coy LAB, Grass Lake, MI, USA 7\% $\mathrm{H}_{2} / 93 \% \mathrm{~N}_{2}$ ). All the solutions used in this study were bubbled with high purity $\mathrm{N}_{2}$ for $2 \mathrm{~h}$ to remove oxygen before being transferred into the anoxic chamber, then exposed to the anoxic atmosphere in the chamber for $48 \mathrm{~h}$. A stock solution of $100 \mathrm{mM}$ $\mathrm{Fe}(\mathrm{II})$ was prepared by dissolving $\mathrm{FeCl}_{2} \bullet 9 \mathrm{H}_{2} \mathrm{O}$ in deoxygenated water inside the anoxic chamber. Similarly, the $100 \mathrm{mM}$ stock solutions of the studied REE ions (denoted by Ln(III) in this study), i.e., $\mathrm{La}(\mathrm{III})$ and $\mathrm{Ho}(\mathrm{III})$, were prepared by dissolving their corresponding chloride salts in deoxygenated water, respectively.

Transformation experiments of ferrihydrite were conducted in $15 \mathrm{~mL}$ plastic tubes as reactors in the anoxic chamber. Each reactor contained $30 \mathrm{mM}$ ferrihydrite $(\sim 3.2 \mathrm{~g} / \mathrm{L}), 0$ or $2.0 \mathrm{mM} \mathrm{Fe}(\mathrm{II})$, and 0 or $1.0 \mathrm{mM} \mathrm{Ln(III).} \mathrm{The} \mathrm{pH}$ of the reaction suspensions was buffered to around 6.5 by $20 \mathrm{mM}$ 1,4-piperazinediethanesulfonic acid (PIPES), which was the typical soil pH condition [20] and also the favored $\mathrm{pH}$ for a high-efficiency $\mathrm{Fe}(\mathrm{II})_{a q}$-induced reaction of iron (hydr)oxides [21]. Background electrolyte was provided by $20 \mathrm{mM} \mathrm{KBr}$ in the buffer. The reagents were added in the order of ferrihydrite, buffer solution, and Ln(III) solution. After equilibrating for $10 \mathrm{~min}$, the Fe(II) solution was finally added to initialize the reactions. The reactors were then immediately sealed with Teflon-coated butyl rubber stoppers and crimp seals. All the reactors were wrapped in Al-foil and placed on an end-to-end rotator. Triplicates out of dozens of incubating reactors were sacrificed to be sampled for analyses at reaction time intervals of $5,10,15,30$, and 60 days.

\subsection{Analyses of Ln(III)}

Two $5 \mathrm{~mL}$ aliquots of suspension were taken from each sample and then placed into centrifuge tubes. After being sealed with an O-ring Teflon tape and covered tightly, the tubes were centrifuged outside the anoxic chamber at $4500 \mathrm{rpm}$ for $10 \mathrm{~min}$. After that, the centrifuge tubes were immediately transferred back into the anoxic chamber, and the supernatant was filtered through $0.22 \mu \mathrm{m}$ nylon filters (Millipore, Burlington, MA, USA) and acidified with $20 \mu \mathrm{L}$ of concentrated $\mathrm{HCl}$ [22,23]. The acidified solution was used to determine the concentrations of dissolved $\mathrm{Ln}(\mathrm{III})$. The solids from the retrieved two aliquots in the centrifuged tubes were extracted by $5 \mathrm{~mL}$ of $0.4 \mathrm{M} \mathrm{HCl}$ for $10 \mathrm{~min}$. After being centrifuged again, the filtrated supernatant was used to determine the adsorbed Ln(III). The solids were then completely dissolved by concentrated $\mathrm{HCl}$ for $1.5 \mathrm{~h}$, and the solutions were used to analyze the stabilized $\operatorname{Ln}(\mathrm{III})$ in the solids [21]. The aqueous concentrations of Ln(III) were determined by 
inductively coupled plasma-optical emission spectroscopy (ICP-OES, Perkin-Elmer optima 2000, Waltham, MA, USA).

\subsection{Characterization of Solid Phase}

The solid phases separated from the centrifugation process of reaction suspensions were washed with DDI water three times and then freeze-dried for characterization. Phase identification and quantification were conducted by XRD analyses on a D8 Advanced Diffractometer (Bruker AXS, Karlsruhe, Germany) with a Lynxeye detector, operating at $40 \mathrm{kV}$ and $40 \mathrm{~mA}$ with $\mathrm{Cu}-\mathrm{K} \alpha$ radiation at room temperature. The standard powder diffraction database of the International Center for Diffraction Data (ICDD PDF-2, Release 2008 [24]) was employed to match the obtained XRD patterns in this study $[25,26]$. Ferrihydrite was considered as amorphous due to its poor crystalline structure in this analysis. In order to quantify both crystalline and amorphous phases, $20 \%(w / w)$ of $\mathrm{CaF}_{2}$ (449717-25G, Merck, Darmstadt, Germany) was added to all samples as the standard reference in the Rietveld quantitative analysis by the total patter solution (TOPAS) program $[27,28]$.

Transmission electron microscopy (TEM, Philips-CM12, FEI, Hillsboro, OR, USA) was applied to observe the morphologies and crystallite sizes of the solid samples before and after Fe(II) $)_{a q}$-induced reactions. According to the methods reported previously [7], the solid samples were dispersed in absolute ethanol ( $\geq 99.5 \%$ ) followed by ultrasonic shaking, and then deposited on holey-carbon film $\mathrm{Cu}$ grids. Afterwards, the images were recorded at $200 \mathrm{kV}$ with the dried grids.

\subsection{Isotope Tracer Experiments for Fe Atom Exchange}

To evaluate the iron atom exchange between $\mathrm{Fe}(\mathrm{III})_{a q}$ and $\mathrm{Fe}(\mathrm{III})_{\text {oxide, }}$ an iron isotope tracer was employed. One hundred millimole per liter of ${ }^{57} \mathrm{Fe}(\mathrm{II})$ stock solution was prepared by dissolving ${ }^{57} \mathrm{Fe}(0)$ powder (Isoflex $>96.0 \%$ ) in $5 \mathrm{M} \mathrm{HCl}$. Except for using ${ }^{57} \mathrm{Fe}(\mathrm{II})$ solution instead of normal $\mathrm{FeCl}_{2} \bullet 9 \mathrm{H}_{2} \mathrm{O}$, all other parameters were used as described for the above procedure in $\mathrm{Fe}(\mathrm{II})_{a q}$-induced ferrihydrite transformation. Since ${ }^{56} \mathrm{Fe}$ accounts for $91.8 \%$ of the total abundances of stable iron isotopes in the natural environment, once the atom exchange between $\mathrm{Fe}(\mathrm{II})_{a q}$ and $\mathrm{Fe}(\mathrm{III})_{\text {oxide }}$ occurred, the replacement of ${ }^{57} \mathrm{Fe}(\mathrm{II})_{a q}$ by ${ }^{56} \mathrm{Fe}(\mathrm{II})_{\text {oxide }}$ would be detected accordingly.

Thus, the iron isotopic fraction was analyzed for the reacted solution using inductively coupled plasma mass spectrometry (ICP-MS, Perkin Elmer NexION 300D, Waltham, MA, USA), operating in a collision cell mode with a glass concentric nebulizer and a HEPA filtered auto-sampler. A collision cell gas containing $93 \% \mathrm{He}$ and $7 \% \mathrm{H}_{2}(>99.999 \%$ pure) was used to eliminate the polyatomic argide molecules $\left(\mathrm{ArO}^{+}\right.$and $\left.\mathrm{ArN}^{+}\right)$at a flow rate of $1 \mathrm{~mL} \cdot \mathrm{min}^{-1}$. All solutions were diluted to around $1 \mu \mathrm{M} \mathrm{Fe}$ with $2 \% \mathrm{HNO}_{3}$ (trace metal grade). Iron isotope fractions $(f)$ were calculated by dividing the counts in each isotope channel by the sum of the total counts over all four channels (i.e., ${ }^{54} \mathrm{Fe},{ }^{56} \mathrm{Fe},{ }^{57} \mathrm{Fe}$ and ${ }^{58} \mathrm{Fe}$ ).

Based on the measurements, the iron atom exchange rates were then calculated according to the following equation [29]:

$$
\text { Fe atom exchange }(\%)=\frac{N_{a q} \times\left(f_{a q}^{i}-f_{F e(I I)}^{t}\right)}{N_{F h}^{T o t} \times\left(f_{F e(I I)}^{t}-f_{F h}^{i}\right)} \times 100
$$

where $N_{a q}$ and $N_{F h}^{T o t}$ are the moles of Fe(II) $)_{a q}$ in the solution and total moles of Fe in ferrihydrite, $f_{a q}^{i}$ and $f_{F h}^{i}$ are the initial isotopic fractions of $\mathrm{Fe}(\mathrm{II})_{a q}$ and ferrihydrite, respectively, and $f_{\mathrm{Fe}(\mathrm{II})}^{t}$ is the isotopic fraction of $\mathrm{Fe}(\mathrm{II})_{a q}$ at time $t$. 


\section{Results and Discussion}

\subsection{Phase Transformation of Ferrihydrite Induced by Fe(II) $)_{a q}$}

Under natural conditions, ferrihydrite is relatively stable except for aging [7]. As examined in our preliminary experiment, no phase transformation of ferrihydrite was observed until 60 days, when $\mathrm{Fe}(\mathrm{II})$ or other cations were absent (data not shown). While under the anaerobic condition with the presence of $2.0 \mathrm{mM} \mathrm{Fe}(\mathrm{II})_{a q}$, a significant phase transformation was detected. As shown in Figure 1A, peaks for goethite and magnetite could be identified from the XRD patterns after 5 days. Peak intensities increased with time, suggesting a continuous transformation from ferrihydrite to goethite and magnetite. With $1.0 \mathrm{mM} \mathrm{La}$ (III) added, the formation of secondary minerals differed. Peaks indicate that lepidocrocite appeared, while goethite and magnetite were not found (Figure 1B). With $1.0 \mathrm{mM} \mathrm{Ho}(\mathrm{III})$ added, XRD patterns clearly shown that ferrihydrite first transformed to lepidocrocite and then finally aged to goethite (Figure 1C). Peak intensities of lepidocrocite increased first and then disappeared later, and goethite peaks kept growing during the whole process. At the end of 60 days of incubation, $\mathrm{Fe}(\mathrm{II})_{a q}$-induced ferrihydrite transformation resulted in different compositions of secondary minerals with or without $\mathrm{Ln}(\mathrm{III})$ presence. A majority of goethite with a minority of magnetite was obtained without Ln(III). Ferrihydrite was transformed to lepidocrocite once La(III) was present. Goethite was the only end product of the transformation under the effect of Ho(III); however, the amount was rather small compared with the absence of Ho(III) and La(III) (CK).

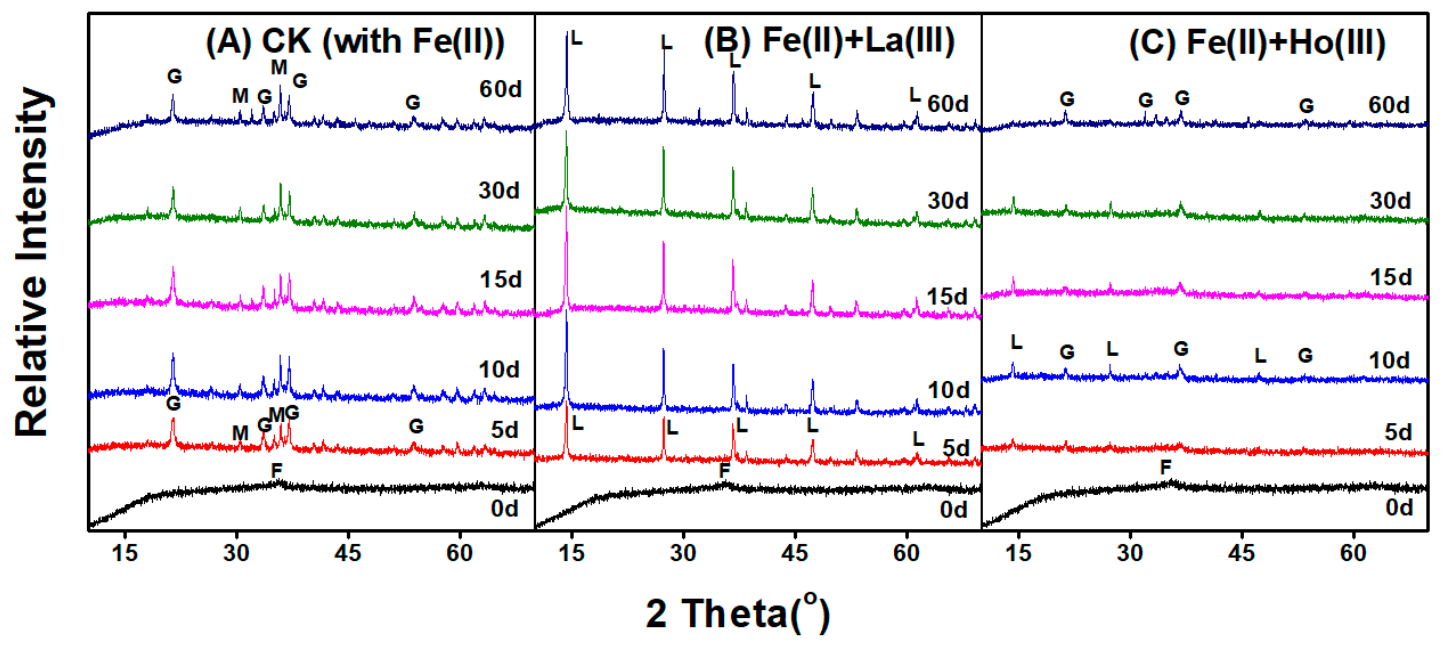

Figure 1. X-ray diffraction (XRD) patterns of the transformed ferrihydrite samples: (A) Fe(II) $)_{a q}$ induced without any $\mathrm{Ln}(\mathrm{III})$; (B) Fe(II) $)_{a q}$ induced with the presence of $\mathrm{La}(\mathrm{III})$; and (C) Fe(II) $)_{a q}$ induced with the presence of $\mathrm{Ho}(\mathrm{III})$. The experiments were conducted at $\mathrm{pH}$ with $2.0 \mathrm{mM}$ of $\mathrm{Fe}(\mathrm{II})_{a q}$ and $1.0 \mathrm{mM}$ of $\mathrm{La}(\mathrm{III})$ or $\mathrm{Ho}(\mathrm{III})$ under anoxic conditions. G: goethite, M: magnetite, L: lepidocrocite, F: ferrihydrite, respectively.

To elucidate the Fe(II) $a q$-induced transformation processes and rates of ferrihydrite with or without REE cations, the TOPAS program was employed to quantitatively analyze the phase compositions of the incubated solids. Changes of three iron (hydr)oxide phase transformation products were obtained in a relative quantity to ferrihydrite (Figure 2). The quantity percentage of ferrihydrite decreased as a result of $\mathrm{Fe}(\mathrm{II})_{a q}$-induced transformation. It was completely transformed to secondary minerals within 10 days in CK, while it took 50 days longer once La(III) was present, suggesting the transformation rate was retarded by $\mathrm{La}(\mathrm{III})$. Under the presence of $\mathrm{Ho}(\mathrm{III})$, about $20 \%$ of ferrihydrite was transformed in the first 10 days, while the transformation seemed stagnant afterwards, suggesting the transformation extent might be inhibited by Ho(III). 
Lepidocrocite was detected in $\mathrm{La}(\mathrm{III})$ or $\mathrm{Ho}(\mathrm{III})$-treated solids during the incubation (Figure 2). Under the treatment of $\mathrm{La}(\mathrm{III})$, consistent with the ferrihydrite decreasing process, the relative quantity of lepidocrocite increased quickly at the beginning, and then the rate slowed down until $100 \%$ of ferrihydrite was transformed to lepidocrocite at 60 days. In contrast, for Ho(III)-treated solids, the relative quantity of lepidocrocite first increased in the first 10 days to around $15 \%$, and later decreased until it completely disappeared at 60 days, suggesting lepidocrocite was further transformed to more stable minerals.

Goethite was the major final product during the $\mathrm{Fe}(\mathrm{II})_{a q}$-induced secondary mineral formation from ferrihydrite without REE cations. About $80 \%$ of ferrihydrite was transformed to goethite within the first 10 days, after which the relative quantity of goethite decreased to around $70 \%$, and eventually transformed to magnetite. No goethite was observed with $\mathrm{La}(\mathrm{III})$ present, while it was found with additional $\mathrm{Ho}$ (III) present. About $20 \%$ of ferrihydrite was transformed to goethite at the end of 60 days with $\mathrm{Ho}(\mathrm{III})$ added. For magnetite, $30 \%$ of the transformed quantity was identified in CK, but a small fraction was found to be affected by additional REE ions.

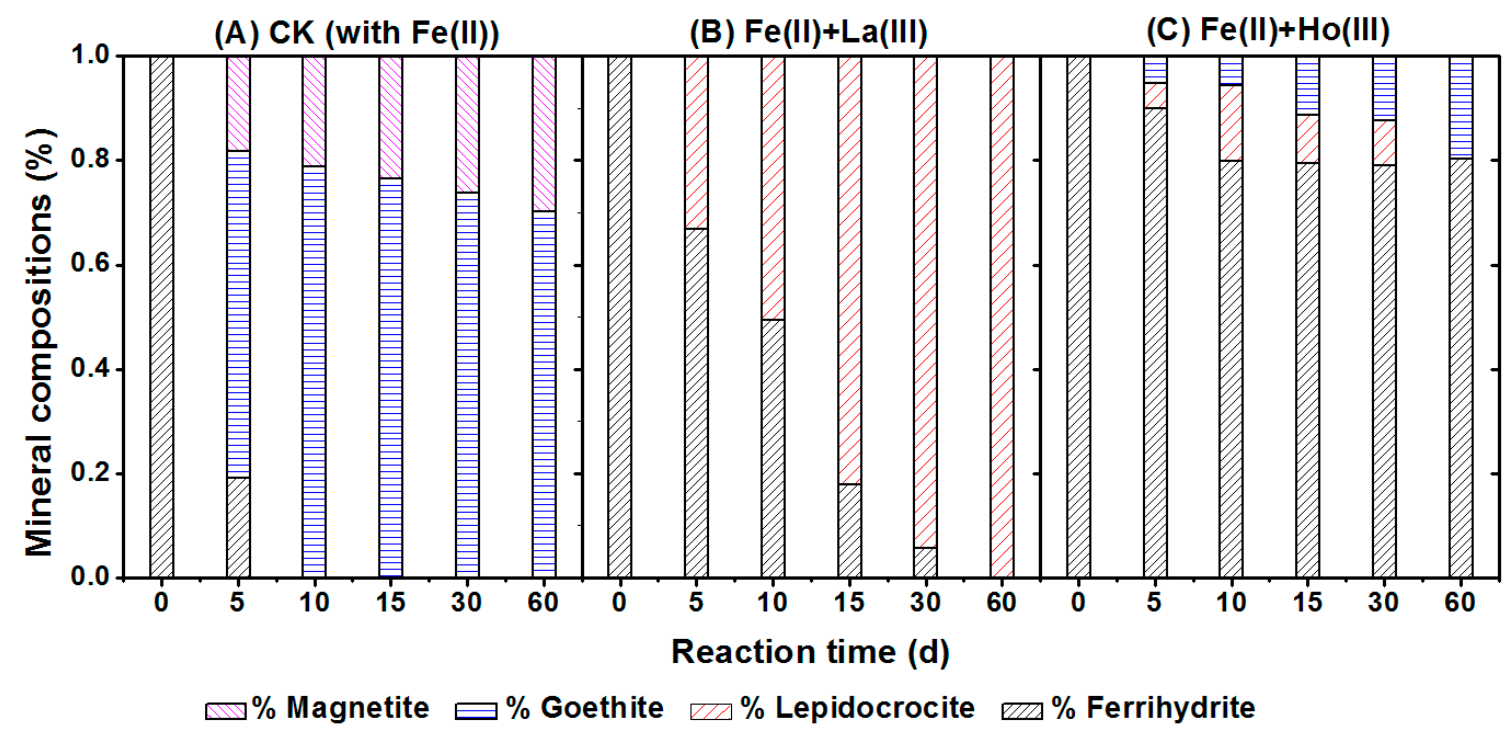

Figure 2. The compositions of iron (hydr)oxides of the transformed ferrihydrite: (A) Fe(II) $)_{a q}$ induced without any $\mathrm{Ln}(\mathrm{III})$; (B) $\mathrm{Fe}(\mathrm{II})_{a q}$ induced with the presence of $\mathrm{La}(\mathrm{III})$; and (C) Fe(II) $)_{a q}$ induced with the presence of $\mathrm{Ho}(\mathrm{III})$.

The TEM images for the final solids obtained at 60 days confirmed the significant differences among the structural forms of the solid products from $\mathrm{Fe}(\mathrm{II})_{a q}$-induced ferrihydrite under conditions without the effects of REEs (CK) and with the effects of $\mathrm{La}$ (III) and Ho(III) (Figure 3).The samples displayed remarkably different appearances under the microscope. Based on the comparison, the star-like particles, indicating the formation of goethite and magnetite [19,30], could be recognized from CK and Ho(III)-added samples, while lath-like lepidocrocite [30] was detected in the La(III)-added sample. 

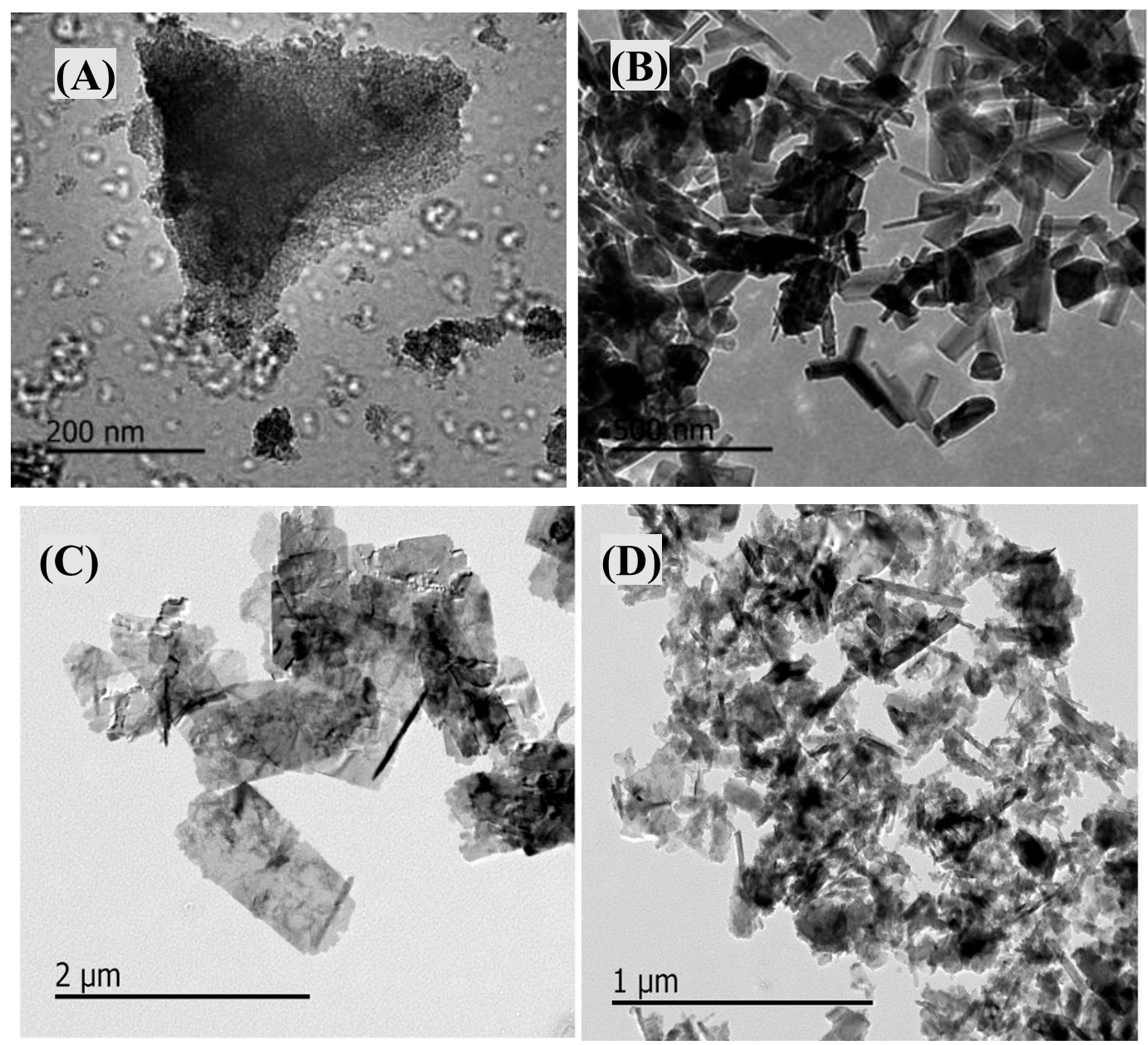

Figure 3. Transmission electron microscope images of ferrihydrite before and after reaction for 60 days in Fe(II)-induced phase transformation: (A) ferrihydrite before reaction; (B) after the Fe(II)-induced reaction without effects of $\mathrm{Ln}(\mathrm{III})$; (C) after the Fe(II)-induced reaction with $\mathrm{La}(\mathrm{III})$; and (D) after the Fe(II)-induced reaction with Ho(III). Reprinted with permission from Ref. [5]. Copyright 2016 Elsevier.

\subsection{Iron Atom Exchange between $\mathrm{Fe}(\mathrm{II})_{a q}$ and $\mathrm{Fe}(\mathrm{III})_{\text {oxide }}$}

Atom exchange is one of the key steps in the process of the phase transformation of ferrihydrite. After $\mathrm{Fe}(\mathrm{II})_{a q}$ was adsorbed on the surface of ferrihydrite, $\mathrm{Fe}(\mathrm{II})_{a q}$ was oxidized to $\mathrm{Fe}(\mathrm{III})_{\text {oxide }}$ due to the electron transfer and $\mathrm{Fe}$ atom exchange, which sequentially drive the transformation of ferrihydrite to more stable minerals [5]. In ${ }^{57} \mathrm{Fe}$ solution, the atom exchange would result in the exchange between ${ }^{57} \mathrm{Fe}_{a q}$ and ${ }^{56} \mathrm{Fe}_{\text {oxide, }}$, which could be detected through isotopic composition changes. Therefore, according to the decrease of ${ }^{57} \mathrm{Fe}$ concentration and increase of ${ }^{56} \mathrm{Fe}$ concentration in the solution, as well as the increase of ${ }^{57} \mathrm{Fe}$ content and decrease of ${ }^{56} \mathrm{Fe}$ content in the mineral phases, the rate of atom exchange can be calculated.

As shown in Figure 4, the calculated atom exchange rates increased during the phase transformation process. The increase was fast at the beginning, and then gradually slowed down, revealing that the most dynamic change occurred within 3 days under all three treatments. After 30 days, the $\mathrm{Fe}(\mathrm{II})_{a q}$-induced ferrihydrite transformation reached $75 \%$ of iron atom exchange when no $\mathrm{Ln}(\mathrm{III})$ co-existed (CK treatment). The co-existent $\mathrm{La}(\mathrm{III})$ and Ho(III) reduced the atom exchange rate to $60 \%$ and $41 \%$, respectively. The co-existent $\mathrm{La}(\mathrm{III})$ and $\mathrm{Ho}(\mathrm{III})$ both inhibited the iron atom exchange rates, but $\mathrm{Ho}(\mathrm{III})$ inhibited it more. This result was consistent with that of previously studied heavy metals $[5,8]$, which resulted from the competitive sorption of $\mathrm{La}(\mathrm{III})$ and $\mathrm{Ho}(\mathrm{III})$ with 
Fe(II). The competition for surface access to ferrihydrite imposed by co-existing cations might be one of the main causes of the inhibited iron atom exchange and, therefore, the inhibited phase transformation.

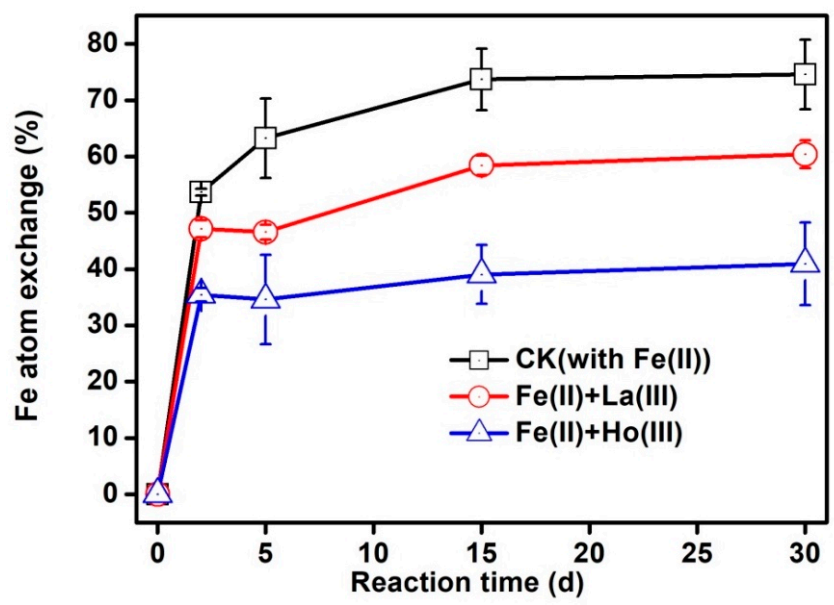

Figure 4. The atom exchange rates between $\mathrm{Fe}(\mathrm{II})_{a q}$ and $\mathrm{Fe}(\mathrm{III})_{\text {oxide }}$ of ferrihydrite during the $\mathrm{Fe}(\mathrm{II})_{a q}$-induced phase transformation of ferrihydrite with or without the coexistence of $\mathrm{Ln}(\mathrm{III})$.

\subsection{Distribution of Ln(III) Species During Fe(II) $)_{a q}$-Induced Transformation of Ferrihydrite}

The process of the $\mathrm{Fe}(\mathrm{II})_{a q}$-induced phase transformation of ferrihydrite would also change the distribution of metallic ion species through adsorption, enwrapping, or substitution [5,6]. To examine the influence of phase transformation on Ln(III) adsorption and immobilization, a differential extraction protocol (described in Section 2.3) was conducted on Ln(III) ions. Beside the dramatic changes within the first 5 days, the distribution of Ln(III) species changed slightly afterwards (Figure 5), while the phase transformation of iron (hydr)oxides occurred dynamically during the whole period of 60 days (Figure 2). The results suggest a high variety between La(III) and Ho(III) (Figure 5). An overwhelming majority of supplemented $\mathrm{La}(\mathrm{III})_{a q}$ remained dissolved in the solution after reacting with ferrihydrite. A smaller portion of $\mathrm{La}$ (III) was stabilized to become structurally incorporated into the secondary iron (hydr)oxide, and the smallest portion was adsorbed. For Ho(III), conversely, the greatest amount was the structural species, followed by adsorbed species, and a very small portion remain dissolved in the aqueous phase.

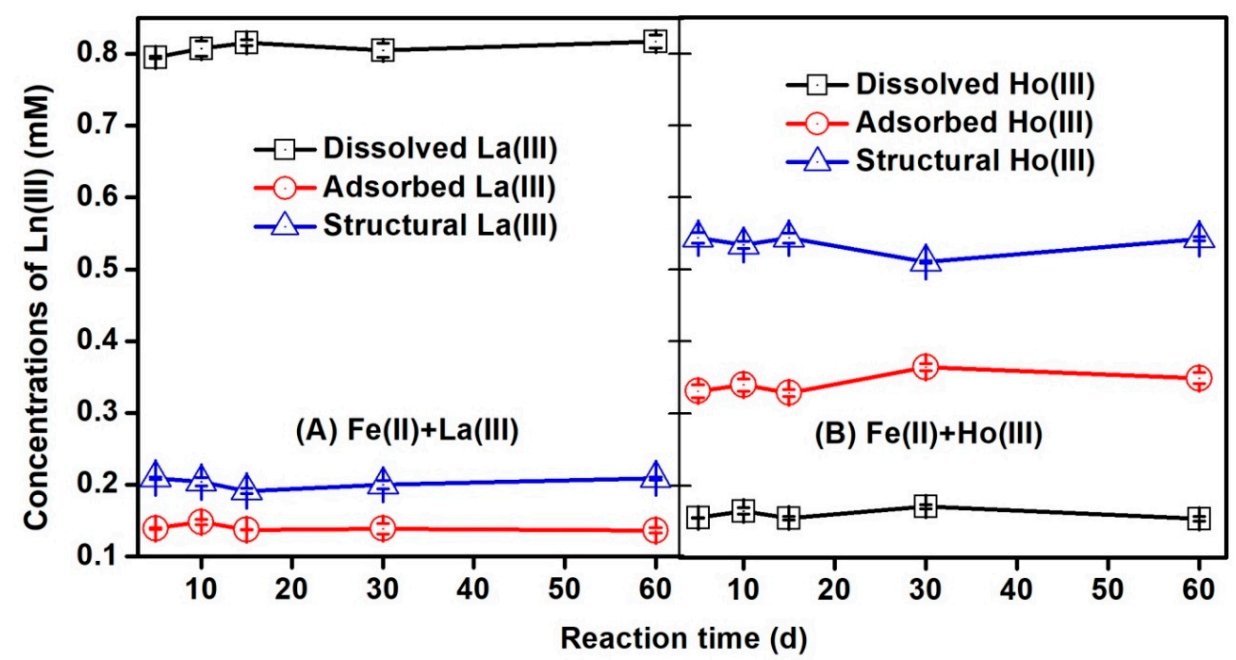

Figure 5. The concentrations of $\mathrm{La}(\mathrm{III})$ (A) and $\mathrm{Ho}(\mathrm{III})$ (B) species during the $\mathrm{Fe}(\mathrm{II})_{a q}$-induced phase transformation of ferrihydrite in the presence of $\mathrm{La}(\mathrm{III})$ and $\mathrm{Ho}(\mathrm{III})$, respectively. 
Remarkably, despite the variety in the amount, the distribution of structural $\operatorname{Ln}(\mathrm{III})$ had a good consistency with adsorbed $\mathrm{Ln}(\mathrm{III})$, as with the less adsorbed $\mathrm{La}$ (III) with less structural $\mathrm{La}(\mathrm{III})$ and the more adsorbed $\mathrm{Ho}(\mathrm{III})$ with more structural Ho(III). Similarly to Fe(II) $)_{a q}$, the attachment to the mineral surfaces was supposed to be the first and critical step for ions to be able to be further incorporated or enwrapped into the lattice of secondary minerals and thus finally immobilized.

\subsection{The Mechanism of Fe(II) $)_{a q}$-Induced Ferrihydrite Transformation Coupled REE Immobilization}

Environmental factors including $\mathrm{pH}$, temperature, $\mathrm{Fe}(\mathrm{II})_{a q}$ concentration, and ionic strength were reported to influence the $\mathrm{Fe}(\mathrm{II})_{a q}$-induced phase transformation of ferrihydrite $[19,25]$. Previous studies stated that metal-substitution in iron (hydr)oxides slowed down the phase transformation [31,32]. The substituted metal could block the reductive dissolution of iron and reduce the bulk electron conduction, thus inhibiting the iron atom exchange or electron exchange between $\mathrm{Fe}(\mathrm{II})_{a q}$ and $\mathrm{Fe}(\mathrm{III})_{\text {oxide }}[6,33]$. The surface adsorption of silica, organic matter, and metal ions would also influence the transformation rate and pathway of ferrihydrite; alternatively, this may change the surface accessibility and reactivity $[5,8,34]$.

Adsorption to the surface of ferrihydrite might be the most important step during the phase transformation process. It was implied that competition with co-existing ions for surface adsorption would be crucial to the phase transformation. As our previous study found [5], the adsorption of $\mathrm{Fe}(\mathrm{II})_{a q}$ had a positive relationship with the rate of the $\mathrm{Fe}(\mathrm{II})_{a q}$-induced transformation of ferrihydrite, while the binding ability of different divalent metal ions (Me(II)), i.e., $\mathrm{Mn}(\mathrm{II}), \mathrm{Mg}(\mathrm{II}), \mathrm{Ca}$ (II), $\mathrm{Ni}(\mathrm{II})$, $\mathrm{Ba}(\mathrm{II}), \mathrm{Co}(\mathrm{II})$ and $\mathrm{Zn}(\mathrm{II})$, imposed negative effects on the ferrihydrite transformation rate. This might have similar effects by $\mathrm{Ln}(\mathrm{III})$ in the present study. It was also found by other researchers that REEs could be adsorbed on the fine grain surface of ferrihydrite, and the adsorption would then impede the crystallization of ferrihydrite [35].

The family of REEs are usually classified to LREEs and HREEs according to their varied behaviors in complexation with ligands, such as carbonate, phosphate, sulphate, oxides as well as organic ligands [36]. LREEs are usually less stably sorbed with organic ligands and minerals than HREEs [37]. In our study, La, as the 'lightest' REE, was indeed sorbed significantly less than the representative HREE, Ho (Figure 5). The difference in the adsorption behavior between La(III) and Ho(III) might be the first cause of the difference in their effect on ferrihydrite transformation. The large surface coverage caused by $\mathrm{Ho}(\mathrm{III})$ adsorption would significantly block the accessibility for $\mathrm{Fe}(\mathrm{II})_{a q}$ and thus limit the ferrihydrite transformation extent, which provides a better explanation for the fact that $\mathrm{Ho}(\mathrm{III})$-treated solids had a lower atom exchange rate than $\mathrm{La}(\mathrm{III})$-treated ones, which were both less than CK (Figure 4).

However, the case of $\operatorname{Ln}(\mathrm{III})$ appeared to be more complicated than the previously studied $\mathrm{Me}(\mathrm{II})$. These results could not simply be explained by binding abilities or competitive adsorption. For the formerly studied Me(II), ferrihydrite transformed from lepidocrocite to goethite and eventually magnetite, while only the transformation rates were different [5]. However, in the present study, the presence of $\mathrm{La}$ (III) significantly slowed the transformation process, taking 60 days longer to achieve the $100 \%$ transformation of original ferrihydrite than that without the effects of $\operatorname{Ln}(\mathrm{III})$ (Figure 2A,B). At the end of incubation, however, this was still half-way through the transformation at the lepidocrocite phase (Figures 1 and 3), whilst for $\mathrm{Ho}(\mathrm{III})$, about $80 \%$ of ferrihydrite did not go through the transformation, though the other $20 \%$ reached the transformed phase of goethite (Figure 2C).

Evidence of the incorporation of adsorbed metals into the secondary iron minerals has been reported $[38,39]$. REEs such as neodymium and lutetium were also found to be incorporated into hematite when transformed from ferrihydrite [40,41]. Different to Fe(II) and $\mathrm{Me}(\mathrm{II})$, the trivalent $\mathrm{Ln}(\mathrm{III})$ used in this study could substitute for Fe(III) $)_{\text {oxide }}$ directly without requiring oxidation to a higher valence. Compared with La (104 pm), Ho has a smaller atomic radius (90 pm) and may have advantages in atom exchange and substitution. 
However, the incorporation or metal-substitution of Ho(III) in iron (hydr)oxides in the present study was found to be limited. As compared with $\mathrm{La}(\mathrm{III})$ in this study and $\mathrm{Me}$ (II) in our previous work [5], the adsorbed species took a small percentage in the species distribution, while a large portion of Ho(III) remained in the adsorbed species (Figure 5). If the incorporation, enwrapping or substitution occurred once the cations were adsorbed, a smaller amount of adsorbed Me(II) or Ln(III) would be detected. Hence, it could be implied that the alteration of adsorbed Ho(III) to structural Ho(III) was limited. It was reasonable that REEs behaved differently with Me(II) when interplayed with iron minerals due to the varied atomic radii, dominant valences and affinities to iron-bearing matters, as well as other physicochemical properties. The successful transformation of the $20 \%$ Ho-treated ferrihydrite to goethite did not bring most of the adsorbed Ho(III) into the crystalline structure, suggesting the adsorption ability of $\mathrm{Ho}$ (III) was larger than the saturated capacity of structural incorporation, resulting in a significant portion of Ho(III) remaining on the mineral surfaces and limiting the surface access to $\mathrm{Fe}(\mathrm{II})_{a q}$. The inhibition of $80 \%$ of the ferrihydrite phase transformation might be strongly related with this.

Based on the discussion above, it is proposed here that the two-step process, i.e., surface adsorption followed by structural incorporation into minerals, imposed significant impacts on the iron (hydr)oxide phase transformation. Given the differences in adsorption affinities and incorporation behaviors, $\mathrm{La}(\mathrm{III})$ and $\mathrm{Ho}$ (III) showed distinguishable performances in influencing the ferrihydrite phase transformation. For $\mathrm{La}(\mathrm{III})$, the competition with $\mathrm{Fe}(\mathrm{II})_{a q}$ in surface adsorption was the main mechanism that retarded the ferrihydrite phase transformation. Afterwards, the incorporation of adsorbed $\mathrm{La}(\mathrm{III})$ into the crystalline structure appeared to be smooth. The recovered surface access allowed for the completion of the $100 \%$ transformation of ferrihydrite, though at a much slower rate. But then, it was possible that the La-substitution made lepidocrocite refractory to be further transformed. Assuming ferrihydrite was transformed through the pathway of lepidocrocite-goethite/magnetite [5], the transformation of La-treated ferrihydrite was not completed. A longer incubation is still necessary to see whether the phase transformation was blocked half-way or not. For Ho(III), the incorporation was relatively small. Hence, $\mathrm{Ho}$ (III)-treated ferrihydrite could go through the whole transformation pathway in 60 days. However, the surface adsorption was rather large, and the limited surface access to $\mathrm{Fe}(\mathrm{II})_{a q}$ resulted in the largely inhibited secondary transformation. It was inferred here that $\mathrm{La}(\mathrm{III})$ and $\mathrm{Ho}$ (III) blocked different steps during the normal phase transformation of ferrihydrite. More studies are required to examine this assumption. Detailed mechanisms involving the incorporation of Ln(III) into iron (hydr)oxides and its influence in the subsequent phase transformation still need further investigations.

Remarkably, it was also observed that the changes of $\operatorname{Ln}(\mathrm{III})$ species were most dynamic within the first 5 days (Figure 5), while changes in iron (hydr)oxide phases lasted longer (Figure 2). As formerly reported, when ferrihydrite was transformed to finer crystallized phases, i.e., goethite and magnetite, the sorption of REEs was decreased; that is, the formerly scavenged $\operatorname{Ln}(\mathrm{III})_{a q}$ would be released to the solution, and LREEs, especially La, were the most sensitive elements to this change [14,42]. However, the changes of $\mathrm{La}$ (III) after 5 days seemed to be random fluctuations, suggesting that the species were not affected by the iron transformation thereafter. The direct inclusion to structural La(III) might protect the adsorbed $\mathrm{La}(\mathrm{III})$ from being desorbed during iron (hydr)oxide transformation, since results showed more structural species than adsorbed species (Figure 5).

\section{Conclusions}

Coexistent REEs play important roles in the $\mathrm{Fe}(\mathrm{II})_{a q}$-induced phase transformation of ferrihydrite as well as resulting in the different adsorption and structural immobilization behaviors of different REEs. The two studied REEs, i.e., the LREE of La(III) and the HREE of Ho(III), both inhibited the phase transformation of ferrihydrite due to their competitive adsorption with $\mathrm{Fe}(\mathrm{II})_{a q}$ on the surface of ferrihydrite and its transformed iron (hydr)oxide products. Because of the low adsorptive affinity of LREEs and the smaller atomic radius, more Ho(III) was adsorbed on the surface of iron minerals, 
which led to the lower phase transformation rates of ferrihydrite than that with $\mathrm{La}(\mathrm{III})$. Accordingly, more $\mathrm{Ho}(\mathrm{III})$ ions were structurally incorporated into the iron mineral products of transformed ferrihydrite induced by Fe(II) $)_{a q}$. These findings highlight the important roles of iron minerals and the phase transformation processes in evaluating the geochemical behavior of different REEs, especially in iron-rich environments.

Author Contributions: Writing-Original Draft preparation, Y.F.; Data curation, J.H.; Investigation, C.L.; Conceptualization, C.L. and F.L.; Writing-Review and Editing, C.L., L.H. and Z.Z.; Validation, F.L. and T.X.; Methodology, M.C., T.G. and Z.W.

Funding: This work was funded by the National Natural Science Foundation of China (U1701241, 41673135, and U1612442), the Frontier Science Research Program of the Chinese Academy of Sciences (CAS) (QYZDB-SSW-DQC046), the Science and Technology Foundation of Guangdong Province, China (2016B020242006 and 2016TX03Z086), the Science and Technology Foundation of Guangzhou, China (201704020200 and 201710010128), the Innovation Team Program of Modern Agricultural Science and Technology of Guangdong Province (2016LM2149), and the One Hundred Talents Program of the CAS.

Conflicts of Interest: The authors declare no conflict of interest.

\section{References}

1. Latta, D.E.; Gorski, C.A.; Scherer, M.M. Influence of $\mathrm{Fe}^{2+}$-catalysed iron oxide recrystallization on metal cycling. Biochem. Soc. Trans. 2012, 40, 1191-1197. [CrossRef] [PubMed]

2. Suter, D.; Siffert, C.; Sulzberger, B.; Stumm, W. Catalytic dissoluion of iron(III)(hydr)oxides by oxalic acid in the presence of Fe(II). Naturwissenschaften 1988, 75, 571-573. [CrossRef]

3. Williams, A.G.; Scherer, M.M. Spectroscopic evidence for $\mathrm{Fe}(\mathrm{II})-\mathrm{Fe}(\mathrm{III})$ electron transfer at the iron oxide-Water interface. Environ. Sci. Technol. 2004, 38, 4782-4790. [CrossRef] [PubMed]

4. Pedersen, H.D.; Postma, D.; Jakobsen, R.; Larsen, O. Fast transformation of iron oxyhydroxides by the catalytic action of aqueous Fe(II). Geochim. Cosmochim. Acta 2005, 69, 3967-3977. [CrossRef]

5. Liu, C.; Zhu, Z.; Li, F.; Liu, T.; Liao, C.; Lee, J.J.; Shih, K.; Tao, L.; Wu, Y. Fe(II)-induced phase transformation of ferrihydrite: The inhibition effects and stabilization of divalent metal cations. Chem. Geol. 2016, 444, 110-119. [CrossRef]

6. Frierdich, A.J.; Scherer, M.M.; Bachman, J.E.; Engelhard, M.H.; Rapponotti, B.W.; Catalano, J.G. Inhibition of trace element release during $\mathrm{Fe}(\mathrm{II})$-activated recrystallization of $\mathrm{Al}-, \mathrm{Cr}-$, and $\mathrm{Sn}$-substituted goethite and hematite. Environ. Sci. Technol. 2012, 46, 10031-10039. [CrossRef] [PubMed]

7. Cornell, R.M.; Schwertmann, U. The Iron Oxides: Structure, Properties, Reactions, Occurrences and Uses, 2nd ed.; Wiley-VCH: Weinhein, Germany, 2003.

8. Liu, C.S.; Li, F.B.; Chen, M.J.; Liao, C.Z.; Tong, H.; Hua, J. Adsorption and stabilization of lead during Fe(II)-catalyzed phase transformation of ferrihydrite. Acta Chim. Sin. 2017, 75, 621-628. [CrossRef]

9. Du, H.; Peacock, C.L.; Chen, W.; Huang, Q. Binding of Cd by ferrihydrite organo-mineral composites: Implications for Cd mobility and fate in natural and contaminated environments. Chemosphere 2018, 207, 404-412. [CrossRef] [PubMed]

10. Freslon, N.; Bayon, G.; Toucanne, S.; Bermell, S.; Bollinger, C.; Cheron, S.; Etoubleau, J.; Germain, Y.; Khripounoff, A.; Ponzevera, E.; et al. Rare earth elements and neodymium isotopes in sedimentary organic matter. Geochim. Cosmochim. Acta 2014, 140, 177-198. [CrossRef]

11. Wang, L.Q.; Liang, T. Geochemical fractions of rare earth elements in soil around a mine tailing in Baotou, China. Sci. Rep. 2015, 5, 12483. [CrossRef] [PubMed]

12. Leybourne, M.I.; Johannesson, K.H. Rare earth elements (REE) and yttrium in stream waters, stream sediments, and Fe-Mn oxyhydroxides: Fractionation, speciation, and controls over REE plus Y patterns in the surface environment. Geochim. Cosmochim. Acta 2008, 72, 5962-5983. [CrossRef]

13. Li, X.; Chen, Z.; Chen, Z.; Zhang, Y. A human health risk assessment of rare earth elements in soil and vegetables from a mining area in Fujian Province, Southeast China. Chemosphere 2013, 93, 1240-1246. [CrossRef]

14. Bolanz, R.M.; Kiefer, S.; Göttlicher, J.; Steininger, R. Hematite (alpha- $\left.\mathrm{Fe}_{2} \mathrm{O}_{3}\right)-\mathrm{A}$ potential Ce ${ }^{4+}$ carrier in red mud. Sci. Total Environ. 2018, 622, 849-860. [CrossRef] [PubMed] 
15. Nedel, S.; Nedel, K.; Dideriksen, B.C.; Christiansen, N.; Bovet, S.L.S.; Stipp, S.L. Uptake and Release of Cerium During Fe-Oxide Formation and Transformation in Fe(II) Solutions. Environ. Sci. Technol. 2010, 44, 4493-4498. [CrossRef] [PubMed]

16. Steinmann, M.; Stille, P. Controls on transport and fractionation of the rare earth elements in stream water of a mixed basaltic-granitic catchment basin (Massif Central, France). Chem. Geol. 2008, 254, 1-18. [CrossRef]

17. Migaszewski, Z.M.; Galuszka, A. The Characteristics, Occurrence, and Geochemical Behavior of Rare Earth Elements in the Environment: A Review. Crit. Rev. Environ. Sci. Technol. 2015, 45, 429-471. [CrossRef]

18. Das, S.; Hendry, M.J.; Essilfie-Dughan, J. Effects of Adsorbed Arsenate on the Rate of Transformation of 2-Line Ferrihydrite at pH 10. Environ. Sci. Technol. 2011, 45, 5557-5563. [CrossRef] [PubMed]

19. Boland, D.D.; Collins, R.N.; Miller, C.J.; Glover, C.J.; Waite, T.D. Effect of solution and solid-phase conditions on the $\mathrm{Fe}(\mathrm{II})$-accelerated transformation of ferrihydrite to lepidocrocite and goethite. Environ. Sci. Technol. 2014, 48, 5477-5485. [CrossRef] [PubMed]

20. Liu, C.S.; Wang, Y.; Li, F.B.; Chen, M.J.; Zhai, G.; Tao, L.; Liu, C. Influence of geochemical properties and land-use types on the microbial reduction of Fe(III) in subtropical soils. Environ. Sci. Process. Impacts 2014, 16, 1938-1947. [CrossRef] [PubMed]

21. Reddy, T.R.; Frierdich, A.J.; Beard, B.L.; Johnson, C.M. The effect of $\mathrm{pH}$ on stable iron isotope exchange and fractionation between aqueous Fe(II) and goethite. Chem. Geol. 2015, 397, 118-127. [CrossRef]

22. Guelke, M.; Blanckenburg, F.; Schoenberg, R.; Staubwasser, M.; Stuetzel, H. Determining the stable Fe isotope signature of plant-available iron in soils. Chem. Geol. 2010, 277, 269-280. [CrossRef]

23. Frierdich, A.J.; Beard, B.L.; Scherer, M.M.; Johnson, C.M. Determination of the Fe(II)aq-magnetite equilibrium iron isotope fractionation factor using the three-isotope method and a multi-direction approach to equilibrium. Earth Planet. Sci. Lett. 2014, 391, 77-86. [CrossRef]

24. ICDD. Powder Diffraction File (PDF 2), Release 2008; International Centre for Diffraction Data: Newtown Square, PA, USA, 2008.

25. Das, S.; Hendry, M.J.; Essilfie-Dughan, J. Transformation of Two-Line Ferrihydrite to Goethite and Hematite as a Function of $\mathrm{pH}$ and Temperature. Environ. Sci. Technol. 2011, 45, 268-275. [CrossRef] [PubMed]

26. Lu, X.W.; Shih, K.M.; Liu, C.S.; Wang, F. Extraction of Metallic Lead from Cathode Ray Tube (CRT) Funnel Glass by Thermal Reduction with Metallic Iron. Environ. Sci. Technol. 2013, 47, 9972-9978. [CrossRef] [PubMed]

27. De La Torre, A.G.; Bruque, S.; Aranda, M.A.G. Rietveld quantitative amorphous content analysis. J. Appl. Crystallogr. 2001, 34, 196-202. [CrossRef]

28. Bernasconi, A.; Dapiaggi, M.; Gualtieri, A.F. Accuracy in quantitative phase analysis of mixtures with large amorphous contents. The case of zircon-rich sanitary-ware glazes. J. Appl. Crystallogr. 2014, 47, 136-145. [CrossRef]

29. Frierdich, A.J.; Helgeson, M.; Liu, C.; Wang, C.; Rosso, K.M.; Scherer, M.M. Iron atom exchange between hematite and aqueous Fe(II). Environ. Sci. Technol. 2015, 49, 8479-8486. [CrossRef] [PubMed]

30. Liu, H.; Li, P.; Zhu, M.Y.; Wei, Y.; Sun, Y.H. Fe(II)-induced transformation from ferrihydrite to lepidocrocite and goethite. J. Solid State Chem. 2007, 180, 2121-2128. [CrossRef]

31. Massey, M.S.; Lezama-Pacheco, J.S.; Michel, F.M.; Fendorf, S. Uranium incorporation into aluminum-substituted ferrihydrite during iron(II)-induced transformation. Environ. Sci. Process. Impacts 2014, 16, 2137-2144. [CrossRef] [PubMed]

32. Masue-Slowey, Y.; Loeppert, R.H.; Fendorf, S. Alteration of ferrihydrite reductive dissolution and transformation by adsorbed As and structural Al: Implications for As retention. Geochim. Cosmochim. Acta 2011, 75, 870-886. [CrossRef]

33. Latta, D.E.; Bachman, J.E.; Scherer, M.M. Fe Electron Transfer and Atom Exchange in Goethite: Influence of Al-Substitution and Anion Sorption. Environ. Sci. Technol. 2012, 46, 10614-10623. [CrossRef] [PubMed]

34. Jones, A.M.; Collins, R.N.; Rose, J.; Waite, T.D. The effect of silica and natural organic matter on the $\mathrm{Fe}(\mathrm{II})$-catalysed transformation and reactivity of Fe(III) minerals. Geochim. Cosmochim. Acta 2009, 73, 4409-4422. [CrossRef]

35. Riley, E.; Dutrizac, J.E. The behaviour of the rare earth elements during the precipitation of ferrihydrite from sulphate media. Hydrometallurgy 2017, 172, 69-78. [CrossRef]

36. Byrne, H.R.; Li, B. Comparative complexation behavior of the rare earths. Geochim. Cosmochim. Acta 1995, 59, 4575-4589. [CrossRef] 
37. Coppin, F.; Berger, G.; Bauer, A.; Castet, S.; Loubet, M. Sorption of lanthanides on smectite and kaolinite. Chem. Geol. 2002, 182, 57-68. [CrossRef]

38. Karthikeyan, K.G.; Elliott, H.A.; Cannon, F.S. Adsorption and coprecipitation of copper with the hydrous oxides of iron and aluminum. Environ. Sci. Technol. 1997, 31, 2721-2725. [CrossRef]

39. Sun, T.; Paige, C.R.; Snodgrass, W.J. The effect of cadmium on the transformation of ferrihydrite into crystalline products at $\mathrm{pH}$ 8. Water Air Soil Pollut. 1996, 91, 307-325. [CrossRef]

40. Nagano, T.; Mitamura, H.; Nakayama, S.; Nakashima, S. Formation of goethite and hematite from neodymium-containing ferrihydrite suspensions. Clays Clay Miner. 1999, 47, 748-754. [CrossRef]

41. Dardenne, K.; Schäfer, T.; Lindqvist-Reis, P.; Denecke, M.A.; Plaschke, M.; Rothe, J.; Kim, J.I. Low temperature XAFS investigation on the lutetium binding changes during the 2-line ferrihydrite alteration process. Environ. Sci. Technol. 2002, 36, 5092-5099. [CrossRef] [PubMed]

42. Bozau, E.; Gottlicher, J.; Stark, H.J. Rare earth element fractionation during the precipitation and crystallisation of hydrous ferric oxides from anoxic lake water. Appl. Geochem. 2008, 23, 3473-3486. [CrossRef]

(C) 2018 by the authors. Licensee MDPI, Basel, Switzerland. This article is an open access article distributed under the terms and conditions of the Creative Commons Attribution (CC BY) license (http://creativecommons.org/licenses/by/4.0/). 